\title{
Investigación jurídica aplicada: Perros en el metro de Barcelona
}

Keywords: perros; ciudades pet friendly; transporte urbano de animales de compañía; Grupo de Investigación ADS-UAB

Los perros van a poder viajar en el Metro de Barcelona en fecha próxima, posiblemente en el verano de 2014. El anuncio público lo hizo el Regidor de Présidencia i Territori del Ajuntament de Barcelona, Excm. Sr. Jordi Martí i Galbis el día 28 de Octubre, con ocasión de la celebración del Salón ANIMALADDA [1], tras llegar el Ayuntamiento a un acuerdo con la Empresa de Transportes Metropolitanos de Barcelona (TMB), que precisa del refrendo de la Generalitat. La noticia ha tenido un amplio eco en la prensa [2], dado que, como se ha subrayado, representa un avance en la inserción de los animales de compañía en el medio urbano y un paso más, de especial significado, en las políticas de tenencia responsable que se vienen desarrollando en Barcelona, desde la Oficina de Protección de los Animales del propio Ayuntamiento, que, por cierto, es la única oficina de estas características en un municipio estatal, cuya responsable es la Sra. Anna Ortonoves. Los que, desde hace unos años, estamos trabajando en este tema y colaborando activamente para que saliera adelante, no nos hemos sorprendido, sino más bien, al contrario, estábamos pendientes de que se hiciera pública la noticia.

Uno de los aspectos que conviene destacar es que, detrás de este logro, hay muchas personas que han desarrollado su trabajo con eficacia, de forma solidaria y con espíritu de colaboración: desde los propios actores de la acción política, pasando por las Asociaciones de Protección de los Animales, a los muchos firmantes de un manifiesto en favor de la aceptación de los perros en los transportes urbanos de Barcelona. Lo que me corresponde ahora, como directora del Grupo de Investigación ADS (AnimalesDerecho-Sociedad) de la UAB, es poner de relieve nuestra contribución -quizá la menos visible- a la consecución de este resultado.

En el año 2011 el Grupo de Investigación ADS concurrió y obtuvo un Proyecto competitivo [3], convocado por el Ayuntamiento de Barcelona, cuyo título era precisamente: "Estrategias de prevención del abandono: transporte de animales de compañía en el medio urbano". El objetivo fundamental del Proyecto era hacer un estudio exhaustivo, comparado, de la normativa de transporte de animales de compañía en el medio urbano y la publicación de los resultados en dos formatos diferentes: el primero de carácter informativo, de cara a usarlo como base de una corrección o mejora de la actual normativa, poco adecuada a la convivencia ciudadana de humanos y de animales, y el segundo, de carácter más científico, como una publicación que recogiera de forma completa el resultado del trabajo realizado. Dichas publicaciones, a la espera de que se produjera la noticia, verán la luz en fecha próxima.

El lema de nuestra investigación ha sido durante este tiempo, transmitir un mensaje sencillo y eficaz: "Transporte urbano, amable y abierto a los animales", o "Transporte pet friendly". Un mensaje que, de forma consolidada, ya se viene practicando en otras ciudades del mundo que se declaran, como Barcelona, ciudades amigas de los animales (=ciudades pet friendly). Las personas del equipo hemos ido desarrollando distintos ámbitos de trabajo: la recogida ordenada de los materiales, para la creación de una base de datos sobre transporte de animales de compañía en el transporte público (Nuria Murlà Ribò, Elisabet Miras, Irene García Colell, Crístina Bécares, Juan Ignacio Serra, Maria Gordillo), la publicación de artículos sobre la legislación comparada (Carlos Contreras), el estudio del sistema de sanciones previsto (José Antonio Jiménez Buendía) y la participación de todos en foros internacionales (Zürich, Bruselas), para dar a conocer y contrastar con otros expertos los progresos del estudio que se estaba llevando a cabo. 
Como anécdota, he de contar que München, la capital de Baviera, se declaró ciudad amiga de los animales en noviembre del 2009 [4], e implantó de forma general el censo de animales, el pago de una tasa por la tenencia de un Animal de Compañía, el libre acceso a los medios de transporte públicos y la obligación de realizar (el perro y el dueño)un curso de capacitación ciudadana. El anuncio de tal cambio normativo, lo hizo el entonces Oberbürgermeister, Christian Ude (SPD), quien se alegraba, con un punto de ironía, del cambio que tales acciones significaban para la ciudad porque, decía: "Die Zamperl haben in München ja schon immer eine große Rolle gespielt.“ (=los de cuatro patas siempre han jugado un papel muy importante en Munich).

La normalización de los Animales de Compañía en el medio urbano, contribuye de forma decisiva a desarraigar una lacra social tan penosa como es el abandono, que, en España, se viene combatiendo con resultados muy visibles desde los últimos años. Los perros callejeros han desaparecido de nuestro paisaje urbano, en cambio hay aún muchos países donde es una asignatura pendiente [5]. No es un tema menor. La UE ha anunciado la promulgación de una legislación marco sobre Animales de Compañía antes del 2015. El propio Ministro de Agricultura de España ha declarado, en fecha reciente, que su Ministerio aspira a regular en breve la situación de los Animales de Compañía.

La investigación no siempre conduce a resultados inmediatos, pero en las Ciencias Jurídicas sí se trata de conseguir cambios en los textos jurídicos, que puedan contribuir, como en este caso se pretendía, a una mejora de la convivencia ciudadana. La aceptación de los Animales de Compañía en el medio urbano, darles acceso a los transportes públicos, junto con las políticas de censo, identificación mediante chip, y obligación de la cartilla sanitaria, constituyen los pilares básicos de una sociedad que reconoce que los Animales de Compañía son parte de la ciudad de hoy en día. Una ciudad que busca fomentar la tenencia responsable y armonizar los intereses de una población donde ellos, "los de cuatro patas", merecen un trato digno. No se puede ignorar el dato de que un gran número de ciudadanos compartimos nuestras vidas con perros o con gatos y que se precisa, sobre todo en momentos de crisis como el que vivimos, facilitar que los animales de compañía, puedan también viajar en transportes públicos. El ejemplo de Barcelona, como el de Múnchen y el de otras muchas ciudades del mundo, es un paso adelante que, estoy segura, van a seguir muchos otros municipios de nuestro país. Que nuestra investigación haya contribuido a este avance, no hace sino estimular nuestro deseo de seguir apoyando desde la Universidad, la mejora del bienestar animal en el ámbito urbano.

LA EDITORA

Teresa Giménez-Candela Catedrática de Derecho Romano Animal Law Profesor

[1] Vid. ANIMALADDA promovido por ADDA, Asociación para la Defensa de los Derechos del Animal, la pionera en España de este ámbito de acción por los animales, desde 1976.

[2] Vid. 20 Minutos, La Vanguardia, Europa Press, Antena3, El Periódico

[3] Ref.:12S04161

[4] Abendzeitung, 9.11.2009

[5] Rumanía, México, Brasil, entre otros, figuran entre los países donde deberían de desarrollarse políticas de control de la población canina y de fomento de la tenencia responsable 